\title{
WHEAT GLUTEN AND COELIAC DISEASE
}

\author{
BY \\ CLAIRE ALVEY, CHARLOTTE M. ANDERSON and MAVIS FREEMAN \\ From the Clinical Research Unit, Royal Children's Hospital, Melbourne
}

(RECEIVED FOR PUBLICATION JUNE 17, 1957)

The relationship between the development of symptoms of coeliac disease and the feeding of wheat flour was first established by Dicke (1950) in Holland. Dicke, Weijers and van de Kamer (1953) confirmed this association by feeding experiments using a quantitative biochemical method in the form of a long-term fat balance to determine the appearance and disappearance of steatorrhoea. Anderson, Frazer, French, Gerrard, Sammons and Smellie (1952), working independently, also demonstrated this correlation and confirmed that gluten or the protein fraction of wheat flour was the deleterious agent causing symptoms and steatorrhoea.

The symptomatology of coeliac disease is largely dependent on inadequate absorption of foodstuffs which occurs when gluten is included in the diet and wheat and rye flour proteins are the only cereal proteins which have been shown conclusively to induce this malabsorption. Several groups of workers have investigated the possible mechanism by which gluten acts deleteriously. The following hypotheses have been suggested and examined : first, 'the allergic hypothesis' or sensitivity of these patients to wheat gluten, and secondly, the 'enzyme hypothesis' or 'alteration in the ability of these patients to digest and absorb gluten. Wheat and rye gluten are different from other cereal proteins in their chemical and physicochemical constitution in that they contain more glutamic acid and proline and can form a type of gel which enables them to be used in breadmaking. Little is known of the chain structure of the gluten molecule and the particular arrangement of peptides in the molecule, but the peptide pattern is probably associated with the gel property. A difference in peptide structure of wheat and rye gluten, together with a difference in the extra- or intracellular enzyme pattern of the coeliac patient might therefore be responsible for the development of symptoms in this disease.

This paper presents some investigations to test these hypotheses and critically assesses other work in this field and makes suggestions concerning future experimental approaches. Although no definite conclusions are drawn it is felt that a record of these investigations will avoid repetition by others or stimulate further ideas.

\section{Allergy to Wheat Gluten}

Although an occasional patient with coeliac disease is noted to react to the taking of gluten very quickly with diarrhoea and vomiting, in the great majority symptoms appear slowly and recede slowly on removal of the offending substance from the diet, and the reaction does not clinically resemble allergy. In none of 28 patients with true coeliac disease studied during the past four years, has there been any history of asthma or finding of eosinophilia in the blood. In only seven patients was there any family history of allergic disease. One child showed eczema which did not clear on removal of gluten from the diet, although the symptoms of coeliac disease did.

Intradermal skin tests using a $2 \%$ gluten solution were carried out on eight patients by one of us (C.M.A.) in England, and on six patients in the present study, with completely negative results.

The suggestion that this reaction to gluten might be an allergic one cannot be upheld by skin testing, therefore.

\section{Digestion and Absorption of Wheat Gluten}

First, digestion of gluten by the extracellular enzymes in the intestinal tract was examined. Secondly, the effect of various digestive products or fractions of gluten, prepared and fed to patients, was tested with especial emphasis on the search for a peptide with a high content of glutamic acid and proline. The absorption of gluten digestive products was then considered, with defective mucosal intracellular enzymes in mind, and blood peptide and amino-acid patterns examined before and after the administration of test doses of gluten.

Extracellular Enzymes. Although it has often been shown in patients with coeliac disease that the 
pancreatic enzymes estimated in duodenal fluid are present in normal quantities, and that gastric juice contains pepsin, the action of these enzymes on wheat gluten itself has not been recorded.

Gastric and duodenal fluids and succus entericus were obtained by intubation from four coeliac patients and allowed to act successively on a $2 \%$ gluten substrate. The $p \mathrm{H}$ in each case was adjusted to that required by the enzyme and the mixture incubated at $37^{\circ} \mathrm{C}$. for a minimal time of three hours for each enzyme. A blank test was made with boiled enzymes and gluten. At the end of the test gluten could be precipitated from the blank on the addition of acetic acid whereas in the tube containing the incubated enzymes it had been digested. The biuret test was negative after the action of the digestive enzymes. Digestion with enzymes from normal children gave a similar result.

This method of testing was not considered to be very sensitive but attempts at identification of digestive products by paper chromatography were foiled by the many interfering amino-acids and peptides in the gastric and duodenal fluids themselves.

From these results it was felt that there was no gross difference in the primary digestion of gluten in normal children and patients with coeliac disease.

Effect of Various Fractions of Gluten. Testing the effect of gluten and any fractions of gluten on patients with coeliac disease in order to obtain a definite quantitative answer involves the performance of a continuous or intermittent fat balance for a considerable number of weeks (Anderson et al., 1952). First, the patient must recover and the fat absorption become normal by removal of gluten from the diet. When the fraction is fed, a negative result cannot be inferred unless absorption remains normal during at least three to four weeks. If a positive result is obtained, this should be checked by a return to normal when the offending fraction is withdrawn. All this involves considerable periods in hospital for the patient and much tedious nursing and laboratory work. Consequently few patients can be studied in this way. However, the following fractions were tested each on one patient by studying the fat excretion in the stools continuously during the period of feeding.

Phospholipid Fraction. This fatty fraction is associated with gluten and can be extracted by fat solvents and separated as an oily substance. Feeding of this to one patient did not produce any increase in fat excretion during one month. However, on subsequent feeding of the gluten from which the phospholipid had been extracted, fat excretion rose to $6 \mathrm{~g}$. a day in two weeks (normal less than $4 \mathrm{~g}$. a day), showing that the toxic property was still present.

TryPtic Digest. Gluten was digested in bulk with pancreatic extract and the product dried and fed to a patient with coeliac disease. The composition of the digest was checked by two-dimensional paper chromatography and shown to be a mixture of peptones and peptides. Feeding of this digest caused a recurrence of steatorrhoea, fat excretion rising to $5.4 \mathrm{~g}$. daily after being stabilized at a level of $3.5 \mathrm{~g}$. daily. Recovery occurred again after withdrawal of the digest.

The tryptic digest was further separated by dialysis through a cellophane membrane. When this dialysate, that is the fraction containing the smaller peptide molecules, was fed for three weeks to a boy, mild clinical symptoms were reproduced and fat excretion rose from 3 to $7 \mathrm{~g}$. per day.

It seemed apparent from these experiments that the peptides from gluten could still harmfully affect patients with coeliac disease.

Amino-ACID Digest. One of us (C.M.A.) working in England had fed an amino-acid digest of gluten (prepared by Bengers Ltd.) to one child with no increase of fat excretion during one month. Therefore complete hydrolysis of gluten seemed to have removed its toxicity. Glutamic acid alone was also given by mouth to a child for one month, in amounts equivalent to that contained in $9 \mathrm{~g}$. of gluten per day, but no increase of fat excretion occurred.

Glutamic Acid-containing Peptides. A fractionation of the bulk tryptic digest was attempted, hoping to isolate peptides containing relatively large amounts of glutamic acid.

Separation with increasing quantities of ethanol was unsuccessful, and a fractionation involving the separation of calcium salts was then made by Foreman's method (1914). Chromatograms of the portion separating at an alcohol concentration of 50 to $95 \%$ showed a peptide containing a greater proportion of glutamic acid and proline than the other fractions. It was also more homogeneous. After removal of the calcium this peptide was fed to a patient but no ill effects resulted. However, it was felt to be an unsatisfactory experiment as larger dosage may have been needed because the peptide could have been altered by manipulation and converted to a non-reactive molecule. Van de Kamer and Weijers (1955) have shown that deamination of whole gluten can make it innocuous and this may have occurred in our manipulations.

Blood Peptides and Amino-acids. As the testing of gluten fractions by feeding and fat balance is so 
tedious and time consuming, requiring large quantities of the substance, and long stay of the patient in hospital, other methods for testing the fate and action of ingested gluten were sought.

It was thought that a study of the blood aminoacid and peptide pattern might be informative. Three normal children and three patients with coeliac disease were given a $30 \mathrm{~g}$. dose of gluten and blood taken two hours later. The blood peptides and amino-acids were studied by two-dimensional paper chromatography. The serum proteins were removed by alcohol and the smaller molecules were fractionated on a Dowex resin (50) column. There was no detectable difference either before or after acid hydrolysis in the chromatogram patterns of the two groups. However, this method could not indicate quantitative differences in peptides, nor variation in the arrangements of the peptide molecules.

Blood Glutamine Estimations. Fasting blood glutamine levels and the rise in values after a test dose of gluten were estimated by the method of Seegmiller, Schwartz and Davidson (1954). This applies microdiffusion for the estimation of glutamine after the specific action of Krebs' glutaminase (1948). The ammonia evolved was measured by nesslerization.

In seven control children fasting levels averaged $7.0 \mathrm{mg}$. \% with a range of 4.9 to 8.7 . The level in 15 coeliac patients was $5.5 \mathrm{mg}$. \% with a range of 2.9 to $8 \cdot 4$. Therefore no significant difference in fasting levels was shown.

Working independently in Holland, Weijers and Van de Kamer (1955) studied blood glutamine curves using the Prescott-Waelsch method. They considered that, following a test feeding of gliadin (350 mg. per kg.) coeliac patients showed an average increase of $100 \%$ in the fasting blood glutamine level, whereas the increase for normals averaged $15 \%$, the highest level being $40 \%$.

In a small series of patients (Table 1) we studied blood glutamine levels two hours after a test dose of $700 \mathrm{mg}$. of gluten per kilogram of body weight. It can be seen in each case and in the average figures that the rise in blood glutamine is three times higher in coeliac patients than in controls. This small series gives similar findings to those of the Dutch workers, but the increase is of a lesser degree. The test dose was $700 \mathrm{mg}$. of gluten per kilogram which corresponded to the $350 \mathrm{mg}$. dose of gliadin (the $70 \%$ alcohol-soluble fraction of gluten) used by Weijers and van de Kamer.

It was thought that this increase in blood glutamine might be used as an index of the toxicity of various gluten fractions, but results were disappointing. Treated cases were used, and comparable doses of fractions given. However, these convalescent patients gave inconsistent results and not always an abnormally high rise of blood glutamine.

\section{Discussion}

While this work has been proceeding, colleagues in both Holland and England have been pursuing very similar investigations. There has for a number of years been a free interchange of ideas between these groups and trends in the work of each group have brought them to the idea that the basic defect in the coeliac child might be a specific alteration or absence of an enzyme, probably a peptidase normally produced in the intestinal mucosal cells. Certain pieces of evidence produced by each group lend some support but no absolute proof to this conception.

Clinically some features favour the conception of a specific developmental defect in this disease. True coeliac disease seems to be a condition occurring in a small number of children when they are exposed to rather specific dietary conditions, that is, when wheat or rye protein is included in their diet. They are healthy before gluten is included in the diet and they react to this protein always or at least until adult. The effect is shown predominantly as an alteration of small intestinal absorbing function, but certain generalized changes are also observed, such

TABLE 1

BLOOD GLUTAMINE VALUES BEFORE AND AFTER A TEST DOSE OF 700 MG. OF GLUTEN PER KILOGRAM BODY WEIGHT

Blood Glutamine (mg. per $100 \mathrm{ml}$. blood)

\begin{tabular}{|c|c|c|c|c|c|}
\hline \multicolumn{3}{|c|}{ Controls } & \multicolumn{3}{|c|}{ Coeliac Patients } \\
\hline Fasting & $\begin{array}{c}\text { Two Hours after } \\
\text { Test Dose }\end{array}$ & $\%$ increase & Fasting & $\begin{array}{l}\text { Two Hours after } \\
\text { Test Dose }\end{array}$ & $\%$ Increase \\
\hline \multirow[t]{2}{*}{$\begin{array}{l}7 \cdot 5 \\
4.9 \\
7.0 \\
8 \cdot 7\end{array}$} & \multirow[t]{2}{*}{$\begin{array}{r}8 \cdot 1 \\
6 \cdot 5 \\
8 \cdot 7 \\
11 \cdot 7\end{array}$} & $\begin{array}{r}8 \\
32 \\
34 \\
34\end{array}$ & \multirow[t]{2}{*}{$\begin{array}{l}4 \cdot 7 \\
2 \cdot 9 \\
7 \cdot 1 \\
3 \cdot 2\end{array}$} & \multirow[t]{2}{*}{$\begin{array}{l}7 \cdot 3 \\
4 \cdot 7 \\
7 \cdot 0 \\
8 \cdot 0\end{array}$} & $\begin{array}{r}55 \\
62 \\
72 \\
128\end{array}$ \\
\hline & & Average $=27$ & & & Average $=79$ \\
\hline
\end{tabular}


as hypotonia and a change in temperament with depressive features. All these things are reversible or reproducible by the subtraction or addition of gluten to the diet. The children are predominantly fair haired and probably all of European descent. These clinical features suggest that the group has some common developmental abnormality which shows up when the offending substance is fed.

The present work produces evidence to discount the idea that this reaction to gluten is an allergic one. Other work has been directed towards finding the specific fraction of gluten which is toxic and which by its identification might give some idea of the possible underlying defect.

Van de Kamer and Weijers (1955) drew attention to the high content of glutamine in wheat and rye gluten but demonstrated that glutamine itself was not toxic to a case of coeliac disease. They went further and showed that by boiling gliadin with $1 \mathrm{~N} \mathrm{HCl}$ a product was obtained in which glutamine was deaminated. This had lost its toxicity and they concluded that glutamine in a bound form was probably the toxic factor.

Frazer (1956), describing the work of his colleagues with gluten fractions, finds that a watersoluble peptide fraction obtained following tryptic digestion possesses the toxic properties of the original gluten. Digestion of this peptide fraction with an extract of pig's intestinal mucous membrane causes disappearance of the toxic effect. They concluded that the effect of gluten was brought about by a glutamine-containing peptide that was probably digested by an enzyme present in the normal intestinal wall but absent in the coeliac child, and postulated a specific enzyme deficiency. They thought that such a concept could explain the observation of van de Kamer and Weijers regarding the reaction of the coeliac child to bound glutamine and the higher content of glutamine in the blood.

The present work has shown that digestion of gluten to the peptide stage appears to take place normally in coeliac children. Complete digestion to the amino-acid stage renders it harmless. However, various intermediate fractions, such as a tryptic digest and a water-soluble dialysate of this, are still active. This seems to indicate that a peptide is probably the harmful substance. The abnormally high increase in blood glutamine following a dose of gluten or gliadin observed by us and Weijers and van de Kamer (1955) indicate that a peptidecontaining glutamine is the toxic fraction.
These features suggest that a specific mucosal peptidase which might deaminate the peptide is absent from the small intestine. However, it is also possible that the removal of glutamine peptides from the bloodstream by the liver may be impaired and that the primary defect lies there and not in the bowel wall. In order to clarify this, further study of the peptidase enzyme pattern of the bowel mucosa and the liver is necessary and also the testing of specific peptides which have glutamine in the terminal position.

Regarding blood glutamine levels this estimation has been suggested by Weijers and van de Kamer (1955) as a diagnostic test for gluten sensitivity but they point out that in some cases results were inconsistent and in a personal communication felt that this test was not always reliable. Our results also suggest unreliability, especially in mild or convalescent patients. In coeliac children, all tests which depend on the rate of absorption from the gut during a period of hours are of doubtful value owing to the generalized upset in the absorbing mechanism of these children. The use of this type of test diagnostically is probably not justified.

\section{Summary}

No evidence of an allergic reaction to wheat gluten can be demonstrated in patients with coeliac disease.

Gluten exerts a harmful effect in these patients whether given as a whole protein or as predigested peptide.

After a dose of gluten, blood glutamine rises to a higher level in coeliac patients than in normal children.

The concept that the toxic effect of gluten is due to a peptide containing glutamine is discussed and a specific intracellular enzyme deficiency postulated.

We wish to thank Mrs. A. Cahn of the Biochemistry Department, Melbourne University, for preparing the 'phospholipid fraction'.

REFERENCES

Anderson, C. M., Frazer, A. C., French, J. M., Gerrard, J. W., Sammons, H. G. and Smellie, J. M. (1952).' Lancet, 1, 836.

Dicke, W. K. (1950). Coeliakie. M.D. Thesis. Utrecht.

- Weijers, H. A. and Kamer, J. H. van de (1953). Acta paediat. (Uppsala), 42, 34.

Foreman, F. W. (1914). Biochem. J., 8, 463.

Foreman, F. W. (1914). Biochem. J., 8, 463. 1009.

Kamer, J. H. van de and Weijers, H. A. (1955). Acta paediat. (Uppsala), 44, 465.

Krebs, H. A. (1948). Biochem. J., 43, 51.

Seegmiller, J. E., Schwartz, R. and Davidson, C. S. (1954). J. clin. Invest., 33, 984.

Weijers, H. A. and Kamer, J. H. van de (1955). Acta paediat. (Uppsala), 44, 536. 